\title{
Australian Chinese and Hong Kong Chinese: How Do They Differ in Primary Control and Secondary Control?
}

\author{
Lai Ching-han Lufanna * \\ Department of Counselling and Psychology, the Hong Kong Shue Yan University, Hong Kong, China \\ ${ }^{*}$ Corresponding author. Email: lufanna@yahoo.com.hk
}

\begin{abstract}
This study investigated whether the relative use of primary and secondary control varies as a function of cultural difference. It is posited that people who are under the influence of Asian, collectivist culture will be oriented toward secondary control than primary control, but vice versa for those in the Western, individualist society [9]. This proposition was tested in this study by using the Chinese respondents from both Australia and Hong Kong. Hence, it is hypothesized that the Australian Chinese will have higher level of primary control but lower level of secondary control than the Hong Kong Chinese. The results revealed that, though the Australian Chinese was significantly higher than Hong Kong Chinese on primary control, they did not differ on secondary control. The result was discussed in terms of integration process in the context of intercultural contact.
\end{abstract}

Keywords: Perceived control, Primary control, Secondary control, Cultural difference, Australian Chinese, Hong Kong Chinese.

\section{INTRODUCTION}

Perceived control is a widely researched construct in psychology. It is important in coping with situations and can be defined as individual judgments of the extent that desired outcomes can be achieved, and potential misfortunes can be guarded against [1] [2] [3].

The highly regarded model of perceived control proposed by Rothbaum et al. [4] divides perceived control into two processes of primary and secondary control. Primary control involves actively changing the environment to fit the needs and desires of the self, and secondary control involves changing one's own thoughts and feelings to fit with the world. It is generally agreed that both primary and secondary control are equally important to maintain individual well-being as they involve taking positive action towards a situation [5] [6]. For instance, Thompson and Spacapan [7] found that perceived control is a major contributor to psychological well-being across the lifespan, with higher level leading to greater happiness, reduced stress, more successful coping, better health and higher self-efficacy.
Perceived control is proposed to operate as a cognitive buffer in the following manner. Under normal conditions where people believe the environment is under their control, they will evidence primary control. In turn, their subjective wellbeing is reinforced [8]. However, when the extrinsic environment cannot be perceived as under one's personal control, secondary control acts as the buffer. That is, if negative life events are perceived as representing a complete loss of control, this would be very damaging to subjective wellbeing. If, on the other hand, people can alter their cognitions in a stressful situation so as to enhance their feelings of control, it helps to buffer against the potentially adverse psychological effects of threatening events [8].

\subsection{Cultural Differences in Control}

Some studies have revealed that the relative use of primary control and secondary control is determined by culture [4] [9] [10]. One of the dimensions to contrast cultures is in terms of individualism and collectivism [11]. In line with this, the Asian culture is viewed as more collectivistic in nature while that of the Western one is characterized as more individualistic [12] [13]. Hui and Triandis [14] posited that people in the 
individualist Western culture are encouraged to strive for personal goals and development of self. Hence, they tend to value autonomy and independence, and to pursue individual achievement. They in turn are less concerned with the mutual obligations of family and friends and more concerned with personal responsibility of one's own life. Contrarily, people in the collectivist Asian society abide by obligation from kinship networks and are encouraged to be loyal to collectivity [14]. They view themselves as interconnected and embedded in interdependent social relationships. In turn, they give priority to the collective interest and subordinate their personal needs to the demands of the family or community [10].

In relation to the use of control, given that people in collectivist society value alignment with the others and selfless subordination to collectivity, it is argued that they will be oriented towards secondary control. That is, they are more inclined to accommodate themselves to the existing realities to maintain harmony and good fit with people around. In the contrary, people in individualist society value autonomy and independence. In this relation, they are more apt to shape existing realities to fit their own wishes by using primary control [9]. Hence, this study attempts to test the above proposition by using the samples of Australian Chinese (AC) and Hong Kong Chinese (HKC). The AC is primarily a migrant group from Hong Kong. As Australia is predominantly an individualist society while Hong Kong is a collectivist one [15], it is predicted that the AC, who are subject to higher influence of individualism, will have higher level of primary control but lower level of secondary control than the HKC .

\section{METHOD}

\subsection{Participants}

Through convenience sampling, 2 groups of samples were drawn as: $\mathrm{AC}(\mathrm{N}=334)$ and $\operatorname{HKC}(\mathrm{N}=698)$. In terms of gender distribution, both groups were slightly dominated by females [AC (females: 57.32\%); HKC (females: 59.68\%)]. In terms of age, the majority of AC $(44.78 \%)$ and HKC $(57.81 \%)$ were in middle adulthood ( 36 - 55 years). Three income levels were used for the Australian Chinese (Low: AU\$30,999 or less; Medium: AU\$31,000 - \$60,000; High: AU\$60,001 and above) [16] and Hong Kong Chinese (Low: HK\$14,999 or less; Medium: HK\$15,000 - \$20,000; High: HK\$20,001 and above) [17]. The income categories correspond with the standard income levels of each country. The income distribution for both groups was that nearly half (AC $43.05 \%$; HKC $49.62 \%$ ) belonged to the high- income group.

\subsection{Measures}

A six-item scale was used as a measure of primary and secondary control. An 11-point end-defined scale was used for all items, with 0 denotes completely disagree and 10 denotes completely agree. This scale was extracted from that of Chambers et al. [18] which originally consists of nine items including the measure of relinquished control. The coefficient alphas of .76 [18] were reported for the nine-item scale. In this study, an alpha of .83 was obtained. The six items are shown as follows:

1. When something bad happens to me, I ask others for help and advice.

2. When something bad happens to me, I look for different ways to improve the situation.

3. When something bad happens to me, I use my skills to overcome the problem.

4. When something bad happens to me, I remind myself something good may come of it.

5. When something bad happens to me, I remind myself I am better off than others.

6. When something bad happens to me, I remind myself situation will improve if I am patient.

\section{RESULTS}

The data were standardized onto a 0-100 scale according to Percentage Scale Maximum scores (\%SM). The t-tests were performed to compare the AC and HKC on the variables of primary control and secondary control. The results are shown below:

Table 1. Chinese respondents in Australia/Hong Kong $x$ Primary Control/ Secondary Control

\begin{tabular}{|l|l|l|l|l|l|l|}
\hline \multirow{2}{*}{ Groups } & \multicolumn{3}{|c|}{ Primary Control } & \multicolumn{3}{|c|}{ Secondary Control } \\
\cline { 2 - 7 } & $\mathrm{N}$ & Mean & SD & $\mathrm{N}$ & Mean & SD \\
\hline $\begin{array}{l}\text { Australia } \\
\text { (AC) }\end{array}$ & 334 & 76.05 & 13.86 & 334 & 73.30 & 16.87 \\
\hline $\begin{array}{l}\text { Hong } \\
\text { Kong } \\
\text { (HKC) }\end{array}$ & 693 & 73.43 & 14.37 & 698 & 72.64 & 17.07 \\
\hline \multicolumn{1}{|c|}{$\mathrm{p}$} & $\mathrm{t}(1025)=-2.77$, & \multicolumn{3}{|c|}{$\mathrm{t}(1030)=-0.59}$, \\
$\mathrm{p}=.006$ & & & & \\
\hline
\end{tabular}

The prediction is partially supported as the mean of primary control for the AC is significantly higher than the HKC. However, secondary control does not differ between them. 


\section{DISCUSSION}

With respect to the use of primary and secondary control, some studies have shown that in the individualistic Western culture, where autonomy and individualism are emphasized, people tend to center on the use of primary control to change the environment in line with their wishes [9] [10]. However, in the collectivist Asian culture that stresses selfless subordination to family and community, people tend to devalue attempts that shape life circumstances in fitting their wishes and are more apt to adopt secondary control [9] [10]. It was therefore hypothesized that, in this study, the AC would have higher level of primary control, but lower level of secondary control, than HKC. The results revealed that, although the $\mathrm{AC}$ is higher than HKC in the use of primary control, there is no difference in secondary control between them.

The results may be explained in terms of the integration process taken place under intercultural contact [11]. When people migrate, such as the AC, it is inevitable that they come into close contact with people of the host culture. In facing the cultural difference between their home country and the host country, an integration process will take place, in that the individuals will embrace the host culture, while also maintain their own cultural values [11]. It may therefore explain the findings that, on one hand, the AC's enhanced primary control is the result of cultural learning which, in turn, increases their orientation to self. But on the other hand, the AC may retain the use of secondary control acquired in home country and hence maintain the same level of secondary control to that of the HKC.

\section{REFERENCES}

[1] Endler, N. S., Kocovski, N. L., \& Macrodimitris, S. D. (2000). Coping, efficacy, and perceived control in acute vs. chronic illness. Canada: York University.

[2] Heckhausen, J. (1999). A model of developmental regulation across the life span. In Developmental regulation in adulthood (pp. 85-101). Cambridge University Press.

[3] Thompson, S. C., Thomas, C., Rickabaugh, C., Tantamjarik, P., Otsuki, T., \& Pan, D., et al. (1998). Primary and secondary control over age-related changes in physical appearance. Journal of Personality, 66, 583-605.

[4] Rothbaum, F., Weisz, J. R., \& Snyder, S. S. (1982). Changing the world and changing the self: A twoprocess model of perceived control. Journal of Personality and Social Psychology, 42, 5-37.

[5] Klein, C. T. F., \& Helweg-Larson, M. (2002). Perceived control and the optimistic bias: A meta-analytic review. Psychology and Health, 17, 437-446.

[6] Skinner, E. A. (1996). A guide to the constructs of control. Journal of Personality and Social Psychology, 71, 549-570.

[7] Thompson, S. C., \& Spacapan, S. (1991). Perceptions of control in vulnerable populations. Journal of Social Issues, 47, 1-21.

[8] Cummins, R. A., Gullone, E., \& Lau, A. L. D. (2002). A model of subjective well-being homeostasis: The role of personality. The Universality of Subjective Well-Being Indicators, 7-46.

[9] Weisz, J. R., Rothbaum, F. M., \& Blackburn, T. C. (1984). Standing out and standing in: The psychology of control in America and Japan. American Psychologist, 39(9), 955-969.

[10] Sastry, J., \& Ross, C. E. (1998). Asian ethnicity and the sense of perceived control. Social Psychology Quarterly, 61(2), 101-120.

[11] Vaughan, G., \& Hogg, M. (2002). Introduction to social psychology. Australia: Prentice Hall.

[12] Al-Zahrani, S. S., \& Kaplowitz, S. (1993). Attributional Biases in Individualistic and Collectivistic Cultures: A Comparison of Americans with Saudis. Social Psychology Quarterly, 56, 223-233.

[13] Liang, B., \& Bogat, G. A. (1994). Culture, Control and Coping: New Perspectives on Social Support. American Journal of Community Psychology, 22, 123-147.

[14] Hui, C. H., \& Triandis, H. C. (1986). Individualism-Collectivism: A Study of CrossCultural Research. Journal of Cross-Cultural Psychology, 17, 225-248.

[15] Hofstede, G. (2017). The Hofstede Centre. https://geert-hofstede.com/countries.html

[16] Cummins, R.A., Woerner, J., Tomyn, A., Gibson, A. and Knapp, T. M. (2007). Australian Unity Wellbeing Index: Report 17.0. The Wellbeing of Australians - Work, Wealth and Happiness. Australian Centre on Quality of Life, School of Psychology, Deakin University, Melbourne.

[17] Census and Statistics Department (2006) 2006 Population By-Census-Summary Results. Hong Kong Government Printer, Hong Kong.

[18] Chambers, S., Hollway, J., Parsons, E-R., \& Wallage, C. (November, 2003). Perceived control and wellbeing. Paper presented at the 5th Australian Conference on Quality of Life, Melbourne, Australia. 